\title{
Utilization of Hospital Room Hospitality Features on Patient-Controlled Tablet Computers: Cohort Study
}

Beiqun Zhao ${ }^{1}$, MD; Ming Tai-Seale ${ }^{2}$, MPH, PhD; Christopher Longhurst ${ }^{3,4}$, MS, MD; Brian Clay ${ }^{4}$, MD

${ }^{1}$ Department of Surgery, University of California San Diego, La Jolla, United States

${ }^{2}$ Department of Family Medicine and Public Health, University of California San Diego, La Jolla, CA, United States

${ }^{3}$ Department of Pediatrics, University of California San Diego, La Jolla, CA, United States

${ }^{4}$ Department of Medicine, University of California San Diego, La Jolla, CA, United States

\section{Corresponding Author:}

Beiqun Zhao, MD

Department of Surgery

University of California San Diego

MC 7220

9300 Campus Point Drive

La Jolla, 92037

United States

Phone: 18582462518

Email: beiqunmzhao@gmail.com

\section{Abstract}

Background: Patient portals tethered to electronic health records can improve patient experience, activation, and outcomes. However, adoption of inpatient portals has been challenging. One way to potentially increase inpatient portal usage is to integrate it with a room control (RC) app on a common tablet computer.

Objective: The aim of this study was to perform a retrospective analysis of patient usage of an RC app provided on tablet computers in patient rooms of our new inpatient tower.

Methods: We identified all patients who were admitted for $>24$ hours to our new inpatient tower over a 90-day period from September 1 to November 30, 2017. After excluding newborn patients from our analysis, we then identified patients who used the RC app at least one time during their admission. We linked these data to patient demographics (including age, sex, and race) and admitting service. We then performed univariable and multivariable logistic regression to assess patterns of RC app usage.

Results: A total of 3411 patients were admitted over the course of the study period; 2242/3411 (65.73\%) used the RC app during their hospitalization. Compared with white patients, other/mixed/unknown race and Asian, Hawaiian, Pacific Islander, American Indian race were significantly associated with increased use of the RC app in a multivariable analysis. Increasing age was significantly associated with increased usage of the RC app. Usage of the RC app also varied by admitting services. Compared with general medicine, bone marrow transplant and general surgery patients had increased usage of the RC app. Conversely, critical care, medical specialties, neurology, surgical subspecialties, and obstetrics/gynecology were all associated with decreased usage of the RC app.

Conclusions: Our study shows that one-third of patients are not using the RC app for critical room functions. Future initiatives to increase RC usage should take these populations into consideration. Contrary to common belief, older patients may use tablet-enabled RCs just as often, if not more often, than younger patients. Certain admitting services, such as neurology and surgical subspecialties, may have had lower usage rates owing to accessibility issues. Our study allows hospitals to tailor support for specific patient populations to increase RC app usage.

(JMIR Mhealth Uhealth 2019;7(6):e13964) doi: 10.2196/13964

\section{KEYWORDS}

inpatients; electronic health records; patient satisfaction; patients' rooms 


\section{Introduction}

Electronic health records with patient portals allow patients to conveniently access their health information, which can improve patient experience, patient activation, and patient care [1-3]. Although outpatient portals are becoming more common, challenges persist in the widespread adoption of inpatient portals [4]. However, it has been shown that colocation of the inpatient portal with a room control (RC) app on a tablet can increase patient utilization of the inpatient portal [5] and may increase patient engagement [6].

In addition, RC apps can centralize frequently used and critical room functions (eg, lighting, curtains, and television controls), thereby enabling patients to better control their environment while being confined to a hospital bed. This has led some to consider RC apps as a hospitality feature for patients, which may be a point of contention in today's health care environment owing to increased concerns over hospital spending on nonclinical amenities [7]. However, hospitality features have been associated with improved patient satisfaction [8,9], which can potentially affect hospital reimbursement [10,11]. In addition, hospitality features and improved patient satisfaction can lead to better patient outcomes [12-15]. For example, empowering patients with $\mathrm{RC}$ apps may reduce calls to nursing staff for room comfort needs, which can decrease patient call-light burden, leading to improved patient care [16].

However, it is not known which patients are more or less likely to use RCs. Answering this question will allow hospitals to tailor support for specific patient populations to increase RC usage. In this study, we have explored our initial experience with implementing an $\mathrm{RC}$ app on tablets in patient rooms at our institution.

\section{Methods}

In designing the patient rooms for our new inpatient tower, our institution made the conscious decision to integrate multiple RCs (eg, curtains, lighting, and television controls) into a central patient-facing app (Crestron Electronics) installed on tablet computers (Apple Inc) in every patient room (Figures 1 and 2).

We sought to examine patient factors associated with using RC features on the tablet. After obtaining institutional review board exemption, we analyzed data over a 90-day period from September 1 to November 30, 2017, for all hospital admissions of $>24$ hours. We examined the proportion of patients who accessed the RC app during their hospitalization by linking RC usage data with patient admission data. After patient linkage, we were able to collect patient demographic information, including sex, age, and race. We also identified the length of stay and admitting service for each patient. This was then categorized into general medicine (including family medicine, internal medicine, and hospitalist services), bone marrow transplant, critical care (including surgical and medical critical care services), general surgery (including transplant, surgical oncology, colorectal, vascular, minimally invasive, and plastic surgery services), medical specialty (including cardiology, pulmonary, medical oncology, and gastroenterology services), neurology (including stroke and neurology services), obstetrics and gynecology, and surgical subspecialty (including urology, head and neck, neurosurgery, and orthopedic surgery services). We excluded newborn patients from our analysis. We performed the Mann-Whitney U test and univariable and multivariable logistic regression analysis using IBM SPSS Statistics (IBM Corp, version 25.0). The level of significance was set at .05 for all analyses.

Figure 1. The main menu of the room control app.

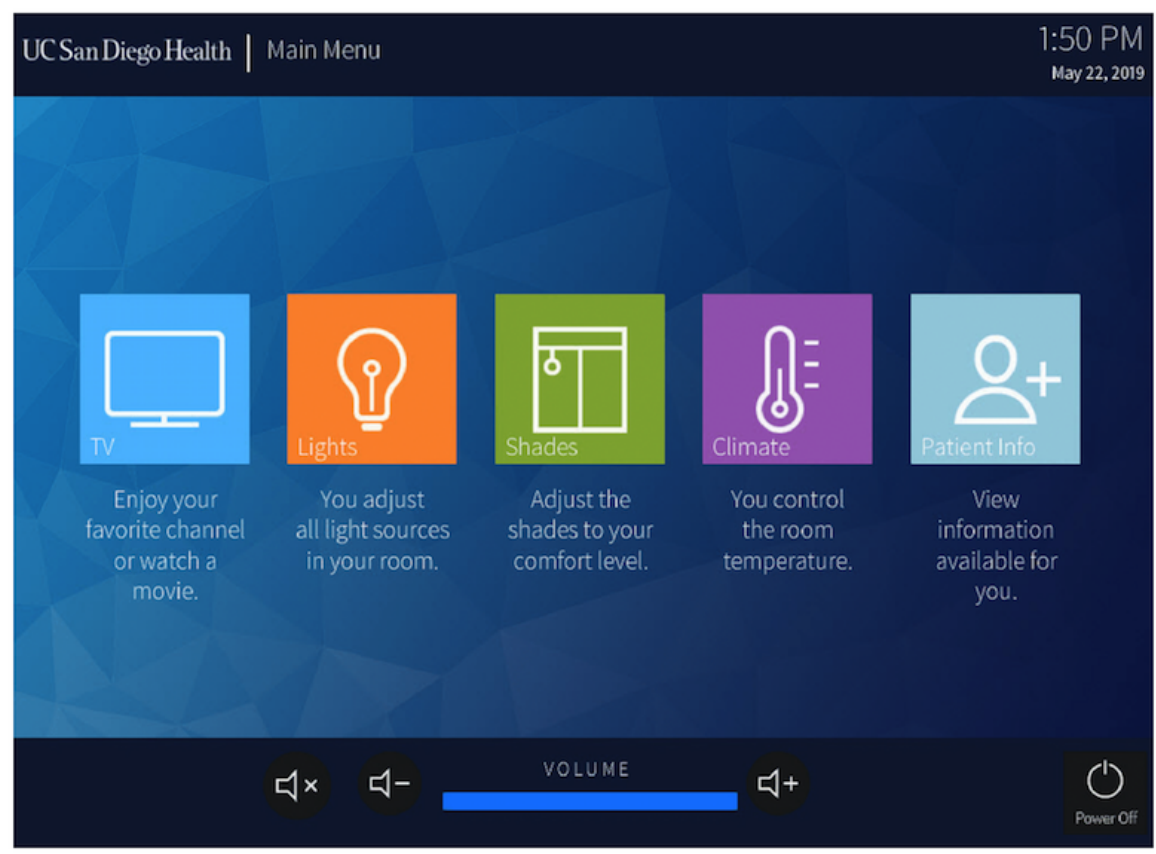


Figure 2. The lighting control submenu of the room control app.

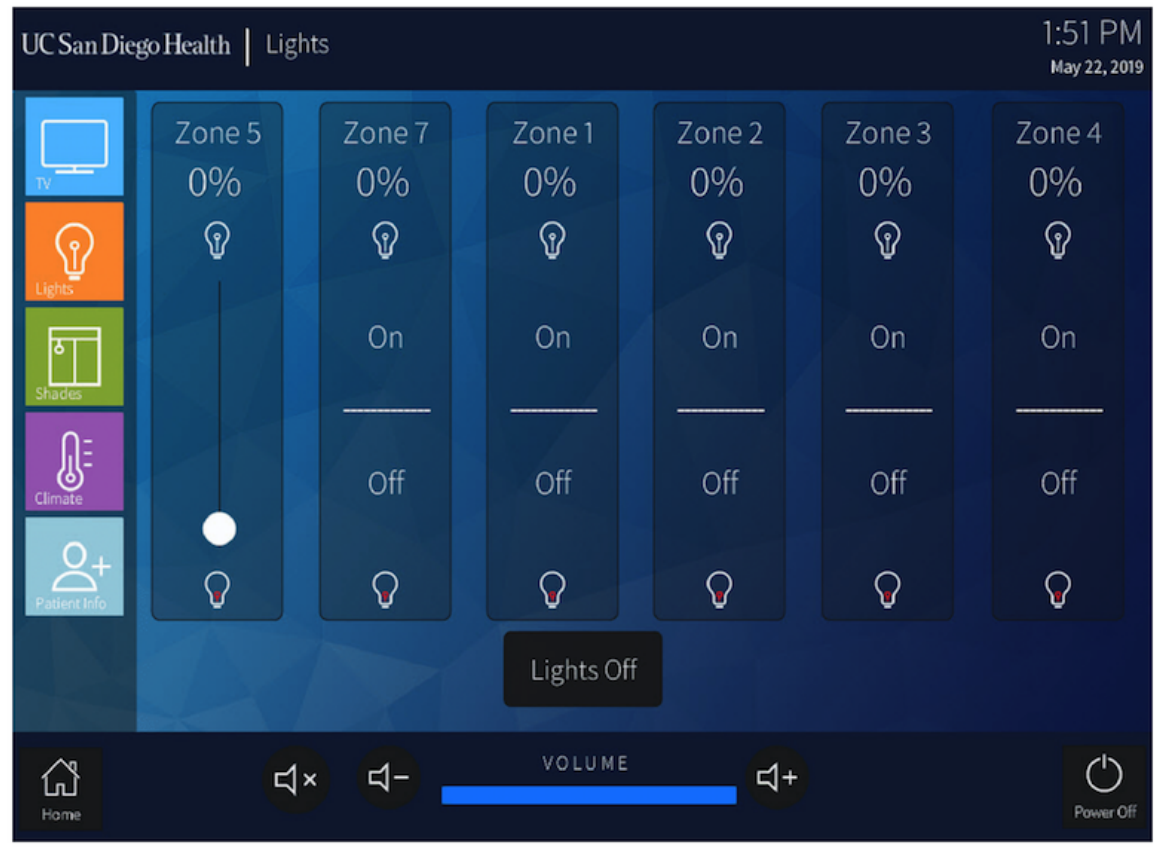

\section{Results}

During our study period, 3411 patients were identified. Of these patients, 2242/3411 (65.73\%) patients used the RC app at some point during their hospitalization. A comparison of sex, age, race, and admitting service is shown in Table 1. Patients who used the RC app had significantly longer hospital length of stay than patients who did not use the RC app $(P<.001)$. Univariable and multivariable logistic regression is shown in Table 2 . In a multivariable analysis, other/mixed/unknown race and Asian, Hawaiian, Pacific Islander, American Indian (AHPIAI) race were associated with increased use of the RC app (odds ratio $[\mathrm{OR}]=1.27 ; P=.008$ and $\mathrm{OR}=1.51 ; P=.006$, respectively) compared with white patients. In addition, increasing age was associated with increased usage of the RC app. Compared with general medicine, bone marrow transplant and general surgery patients had increased usage of the RC app. Conversely, critical care, medical specialty, neurology, surgical subspecialty, and obstetrics/gynecology were all associated with decreased usage. 
Table 1. Patient demographics stratified by room control app usage (N=3411).

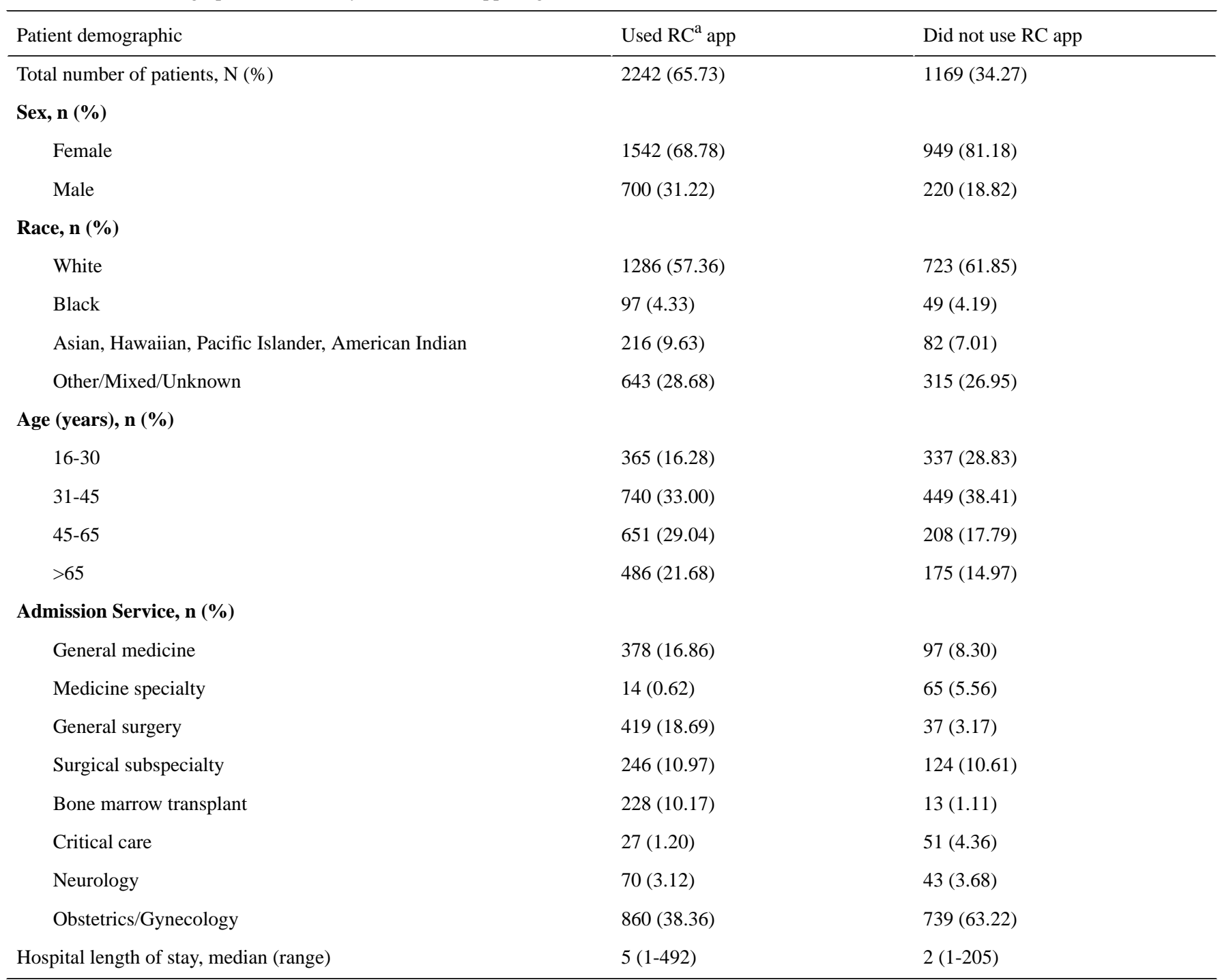

${ }^{\mathrm{a}} \mathrm{RC}$ : room control. 
Table 2. Univariable and multivariable logistic regression.

\begin{tabular}{|c|c|c|c|c|}
\hline \multirow[t]{2}{*}{ Variables } & \multicolumn{2}{|c|}{ Univariable analysis } & \multicolumn{2}{|c|}{ Multivariable analysis } \\
\hline & $P$ value & Odds ratio $(95 \% \mathrm{CI})$ & $P$ value & Odds ratio $(95 \% \mathrm{CI})$ \\
\hline Female & $<.001$ & $0.511(0.430-0.606)$ & .28 & $-^{\mathrm{a}}$ \\
\hline \multicolumn{5}{|l|}{ Race } \\
\hline White & - & Reference & - & Reference \\
\hline Black & .555 & - & .31 & - \\
\hline Asian, Hawaiian, Pacific Islander, American Indian & .004 & $1.481(1.130-1.940)$ & .006 & $1.510(1.129-2.020)$ \\
\hline Other/Mixed/Unknown & .097 & - & .008 & $1.274(1.064-1.526)$ \\
\hline \multicolumn{5}{|l|}{ Age (years) } \\
\hline $16-30$ & - & Reference & - & Reference \\
\hline $31-45$ & $<.001$ & $1.522(1.260-1.838)$ & $<.001$ & $1.494(1.225-1.822)$ \\
\hline $45-65$ & $<.001$ & $2.890(2.330-3.583)$ & .002 & $1.591(1.179-2.149)$ \\
\hline$>65$ & $<.001$ & $2.564(2.042-3.219)$ & .006 & $1.586(1.140-2.204)$ \\
\hline \multicolumn{5}{|l|}{ Admission service } \\
\hline General medicine & - & Reference & - & Reference \\
\hline Medicine specialty & $<.001$ & $0.055(0.030-0.103)$ & $<.001$ & $0.036(0.018-0.071)$ \\
\hline General surgery & $<.001$ & $2.906(1.9414 .350)$ & $<.001$ & $3.288(2.186-4.944)$ \\
\hline Surgical subspecialty & $<.001$ & $0.509(0.3730 .694)$ & .001 & $0.588(0.427-0.808)$ \\
\hline Bone marrow transplant & $<.001$ & $4.501(2.4668 .215)$ & $<.001$ & $3.288(2.186-4.944)$ \\
\hline Critical care & $<.001$ & $0.136(0.081-0.228)$ & $<.001$ & $0.104(0.060-0.180)$ \\
\hline Neurology & $<.001$ & $0.418(0.269-0.649)$ & .001 & $0.472(0.302-0.739)$ \\
\hline Obstetrics/Gynecology & $<.001$ & $0.299(0.234-0.381)$ & $<.001$ & $0.490(0.352-0.681)$ \\
\hline Hospital length of stay & $<0.001$ & $1.056(1.043-1.069)$ & $<.001$ & $1.040(1.025-1.054)$ \\
\hline
\end{tabular}

${ }^{\mathrm{a}}$ Not applicable.

\section{Discussion}

\section{Principal Findings}

We found that $65.7 \%$ of patients admitted to our new inpatient tower used an integrated RC app installed on tablet computers inside patient rooms. After controlling for other predictors, we found that the AHPIAI race and other/mixed/unknown race was associated with increased RC app use. Surprisingly, we also found that increasing age was associated with increased $\mathrm{RC}$ app use. In addition, longer hospital length of stays were predictive of RC app usage. Finally, compared with general medicine, patients admitted to general surgery and bone marrow transplant had more RC app use, whereas patients admitted to medicine specialty, surgical subspecialty, critical care, neurology, and obstetrics/gynecology all had less RC app use than general medicine.

There has been growing concerns that elderly patients may be disadvantaged by the influx of technology in health care today [17]. However, in our study, we found that as age increased, use of the RC app also increased. This may be partly explained by the intuitive nature of the tablet interface, and previous literature has shown success in using tablet-based apps in elderly patients [18]. Furthermore, this finding showcases that RC apps

can potentially function as a gateway for elderly patients to access other patient-facing technology.

\section{Secondary Findings}

Another interesting finding is the large variation in $\mathrm{RC}$ use among admitting services. Patients admitted to the bone marrow transplant service may have had the highest rate of RC app usage because these patients are often admitted to the hospital for prolonged periods of time. However, even after controlling for length of stay, these patients were still more likely to use the RC app. This is most likely because their movement in and out of their unit is limited owing to their disease process and are thereby more likely to explore hospitality features. Increased use of the RC app in general surgery patients may be because these patients are often confined to their hospital beds after surgery and are unable to control the blinds or lights through the usual physical switches on the wall. In this case, the RC app gives patients more control over their environment, which may improve the patient experience during a highly vulnerable time. This pattern is not seen in surgical subspecialty patients, potentially because these patients, especially neurosurgery, head and neck surgery, and orthopedic surgery patients, may not be physically able to operate a tablet computer after surgery. This may also explain the decreased usage of RCs in neurology patients. Therefore, further work will be needed to increase 
accessibility in these patients (perhaps through voice-enabled features). Patients admitted to the critical care service are clinically very sick, which may limit their usage of ancillary technology such as tablet computers. Similarly, medicine subspecialty patients may also represent a group of patients with high clinical acuity. Obstetrics and gynecology represent a very diverse group of patients, making interpretations difficult with regard to their usage of the RC app. Future studies will focus on barriers to RC app usage unique to each admitting service and exploring potential ways to increase $\mathrm{RC}$ app usage for each service.

\section{Limitations}

Given its retrospective nature, we are unable to ensure that RCs were used by the patient and not by a family member. However, $\mathrm{RC}$ app use by family members may still encourage use of other apps found on the tablet. It is also possible that the RC app was used by the nursing staff to demonstrate the RCs to the patient, though we suspect this occurrence is rare. Interpretation of use patterns of obstetrics and gynecology patients was difficult because they represent a diverse group of patients, with different indications and acuity. This service includes patients admitted to labor and delivery for observation and patients undergoing postoperative care after a large cancer operation. The former group may be more similar to general medicine patients, whereas the latter group may be more similar to general surgery patients. Unfortunately, we are unable to separate the different obstetrics/gynecology patients in the current analysis. Although RC apps may increase inpatient portal usage [5], we are unable to track the usage of other apps on the tablet at this time. In addition, we do not have granular data of RC app usage, such as average daily use length and specific features accessed. Obtaining this type of data may require a prospective analysis (ie, installing a tracking software) and will be a source of future studies. In addition, patient-level data, such as income and education, were not available. These factors may play a role in the adoption of the $\mathrm{RC}$ apps.

\section{Conclusions}

Our study shows that approximately one-third of patients are not using the RC app to control critical room functions, and future initiatives to increase RC app usage should take these populations into consideration. Despite its intuitive interface, there may still be accessibility limitations to the current RC app, especially for patients admitted to certain services. A more thorough exploration of why the RC app usage is low in these patient populations is needed in the future.

\section{Acknowledgments}

The authors would like to acknowledge the following for their uncompensated assistance in obtaining data for this study: Marc Sylwestrzak BS, Shuxiang Liu MS, and Calvin Fong BS, Information Technology Services Department, University of California San Diego, La Jolla, CA.

BZ is funded by the National Library of Medicine Training Grant: National Institutes of Health grant T15LM011271.

\section{Conflicts of Interest}

None declared.

\section{References}

1. Vawdrey DK, Wilcox LG, Collins SA, Bakken S, Feiner S, Boyer A, et al. A tablet computer application for patients to participate in their hospital care. AMIA Annu Symp Proc 2011;2011:1428-1435 [FREE Full text] [Medline: 22195206]

2. Otte-Trojel T, de Bont A, Rundall TG, van de Klundert J. How outcomes are achieved through patient portals: a realist review. J Am Med Inform Assoc 2014;21(4):751-757. [doi: 10.1136/amiajnl-2013-002501] [Medline: 24503882]

3. Collins SA, Rozenblum R, Leung WY, Morrison CR, Stade DL, McNally K, et al. Acute care patient portals: a qualitative study of stakeholder perspectives on current practices. J Am Med Inform Assoc 2017 Apr 1;24(e1):e9-17. [doi: 10.1093/jamia/ocw081] [Medline: 27357830]

4. Otte-Trojel T, de Bont A, Rundall TG, van de Klundert J. What do we know about developing patient portals? A systematic literature review. J Am Med Inform Assoc 2016 Apr;23(e1):e162-e168 [FREE Full text] [doi: 10.1093/jamia/ocv114] [Medline: 26335985]

5. Tai-Seale M, Downing NL, Jones VG, Milani RV, Zhao B, Clay B, et al. Technology-enabled consumer engagement: promising practices at four health care delivery organizations. Health Aff (Millwood) 2019 Mar;38(3):383-390. [doi: 10.1377/hlthaff.2018.05027] [Medline: 30830826]

6. McAlearney AS, Sieck CJ, Hefner JL, Aldrich AM, Walker DM, Rizer MK, et al. High touch and high tech (HT2) proposal: transforming patient engagement throughout the continuum of care by engaging patients with portal technology at the bedside. JMIR Res Protoc 2016 Nov 29;5(4):e221 [FREE Full text] [doi: 10.2196/resprot.6355] [Medline: 27899338 ]

7. Rosenthal E. New York Times. 2013 Sep 21. Is This a Hospital or a Hotel? URL: https://www.nytimes.com/2013/09/22/ sunday-review/is-this-a-hospital-or-a-hotel.html

8. Wu Z, Robson S, Hollis B. The application of hospitality elements in hospitals. J Healthc Manag 2013;58(1):47-62; discussion 62-3. [Medline: 23424818] 
9. Wensley C, Botti M, McKillop A, Merry AF. A framework of comfort for practice: an integrative review identifying the multiple influences on patients' experience of comfort in healthcare settings. Int J Qual Health Care 2017 Apr 1;29(2):151-162. [doi: 10.1093/intqhe/mzw158] [Medline: 28096279]

10. Mehta SJ. Patient satisfaction reporting and its implications for patient care. AMA J Ethics 2015 Jul 1;17(7):616-621 [FREE Full text] [doi: 10.1001/journalofethics.2015.17.7.ecas3-1507] [Medline: 26158808]

11. Medicare. 2019. Survey of Patients' Experience (HCAHPS) URL: https://www.medicare.gov/hospitalcompare/Data/ Overview.html [accessed 2019-03-07]

12. Sacks GD, Lawson EH, Dawes AJ, Russell MM, Maggard-Gibbons M, Zingmond DS, et al. Relationship between hospital performance on a patient satisfaction survey and surgical quality. JAMA Surg 2015 Sep;150(9):858-864. [doi: 10.1001/jamasurg.2015.1108] [Medline: 26108091]

13. Glickman SW, Boulding W, Manary M, Staelin R, Roe MT, Wolosin RJ, et al. Patient satisfaction and its relationship with clinical quality and inpatient mortality in acute myocardial infarction. Circ Cardiovasc Qual Outcomes 2010 Mar;3(2):188-195 [FREE Full text] [doi: 10.1161/CIRCOUTCOMES.109.900597] [Medline: 20179265]

14. Boulding W, Glickman SW, Manary MP, Schulman KA, Staelin R. Relationship between patient satisfaction with inpatient care and hospital readmission within 30 days. Am J Manag Care 2011 Jan;17(1):41-48 [FREE Full text] [Medline: 21348567]

15. Trzeciak S, Gaughan JP, Bosire J, Mazzarelli AJ. Association between medicare summary star ratings for patient experience and clinical outcomes in US hospitals. J Patient Exp 2016 Apr 7;3(1):6-9. [doi: 10.1177/2374373516636681]

16. Tzeng HM. Perspectives of staff nurses of the reasons for and the nature of patient-initiated call lights: an exploratory survey study in four USA hospitals. BMC Health Serv Res 2010 Feb 26;10:52. [doi: 10.1186/1472-6963-10-52] [Medline: 20184775]

17. Anthony DL, Campos-Castillo C, Lim PS. Who isn't using patient portals and why? Evidence and implications from a national sample Of US adults. Health Aff (Millwood) 2018 Dec;37(12):1948-1954. [doi: 10.1377/hlthaff.2018.05117] [Medline: $\underline{30633673]}$

18. Mehra S, Visser B, Cila N, van den Helder J, Engelbert RH, Weijs PJ, et al. Supporting older adults in exercising with a tablet: a usability study. JMIR Hum Factors 2019 Feb 1;6(1):e11598. [doi: 10.2196/11598] [Medline: 30707106]

\author{
Abbreviations \\ AHPIAI: Asian, Hawaiian, Pacific Islander, American Indian \\ OR: odds ratio \\ RC: room control
}

Edited by G Eysenbach; submitted 08.03.19; peer-reviewed by A Chan, M Whelan; comments to author 06.05.19; revised version
received 23.05.19; accepted 23.05.19; published 20.06.19
Please cite as:
Zhao B, Tai-Seale M, Longhurst C, Clay B
Utilization of Hospital Room Hospitality Features on Patient-Controlled Tablet Computers: Cohort Study
JMIR Mhealth Uhealth 2019;7(6):e13964
URL: $\underline{\text { http://mhealth.jmir.org/2019/6/e13964/ }}$
doi: $10.2196 / 13964$
PMID: $\underline{31223118}$

(CBeiqun Zhao, Ming Tai-Seale, Christopher Longhurst, Brian Clay. Originally published in JMIR Mhealth and Uhealth (http://mhealth.jmir.org), 20.06.2019. This is an open-access article distributed under the terms of the Creative Commons Attribution License (https://creativecommons.org/licenses/by/4.0/), which permits unrestricted use, distribution, and reproduction in any medium, provided the original work, first published in JMIR mhealth and uhealth, is properly cited. The complete bibliographic information, a link to the original publication on http://mhealth.jmir.org/, as well as this copyright and license information must be included. 